\title{
Predictive significance of arachidonate 15-lipoxygenase for eosinophilic chronic rhinosinusitis with nasal polyps
}

Zhuoping Liang ${ }^{1,2+}$, Bing Yan ${ }^{1,2,4 \dagger}$, Chang Liu ${ }^{1,2}$, Ruyu Tan ${ }^{1,2}$, Chengshuo Wang ${ }^{1,4^{*}}$ and Luo Zhang ${ }^{1,2,3,4^{*}}$ (D)

\begin{abstract}
Background: Eosinophilic chronic rhinosinusitis with nasal polyps (ECRSwNP) exhibits a poorer outcome compared with non-eosinophilic chronic rhinosinusitis with nasal polyps (nonECRSwNP), so it is significant to identify effective markers to differentiate ECRSWNP in guiding the treatment strategies of these patients. Although arachidonate 15-lipoxygenase (ALOX15) is positioned as a marker of eosinophilic inflammation, its study in differentiating ECRSwNP has not been reported. The aim of this study is to assess the potential of ALOX15 in distinguishing and predicting ECRSWNP.

Methods: Forty-eight patients with chronic rhinosinusitis with nasal polyps (CRSwNP), including 30 ECRSwNP and 18 nonECRSwNP patients, were enrolled. ALOX15 mRNA level was determined in polyps by real-time polymerase chain reaction (RT-PCR). The patients' baseline characteristics were evaluated and analyzed for correlations with ALOX15. Receiver operating characteristic (ROC) curve was used to assess the predictive significance of the potential predictors for ECRSWNP.

Results: ALOX15 mRNA level was significantly higher in ECRSwNP patients than in nonECRSwNP patients $(P<0.001)$. ALOX15 mRNA was significantly correlated with tissue and blood eosinophil percentages $(r=0.565, P<0.001$ and $r=0.395, P=0.006)$, olfaction scores $(r=0.400, P=0.005)$, total visual analogue scale (VAS) symptom scores $(r=0.383$, $P=0.007)$, ethmoid/maxillary sinus ( $E / M)$ ratio $(r=0.463, P=0.001)$, and endoscopy scores $(r=0.409, P=0.004)$. Logistic regression analysis showed ALOX15 mRNA level and percentage of blood eosinophils to be predictive factors for ECRSWNP ( $P=0.004$ and $P=0.036$, respectively). ROC curve indicated ALOX15 to have high predictive accuracy for ECRSwNP (area under the curve $(A \cup C)=0.909$ ), which was further improved by combination of ALOX15 with percentage of blood eosinophils $(A \cup C=0.933)$.
\end{abstract}

Conclusions: The relative ALOX15 mRNA level alone or in combination with blood eosinophils might be a reliable biomarker for predicting a diagnosis of ECRSWNP.

Keywords: Arachidonate 15-lipoxygenase, Biomarker, Chronic rhinosinusitis with nasal polyps, Eosinophils, Predictive value, Receiver operating characteristic curve

*Correspondence: wangcs830@126.com; dr.luozhang@139.com ${ }^{\dagger}$ Zhuoping Liang and Bing Yan contributed equally to this study ${ }^{1}$ Department of Otolaryngology, Head and Neck Surgery, Beijing TongRen Hospital, Capital Medical University, Beijing 100730, People's Republic of China

Full list of author information is available at the end of the article

\section{Introduction}

Chronic rhinosinusitis with nasal polyps (CRSwNP) is a spectrum of heterogeneous diseases. Based on the degree of infiltrating eosinophils, CRSwNP is subclassified into eosinophilic CRSwNP (ECRSwNP) and noneosinophilic CRSwNP (nonECRSwNP) [1-3]. ECRSwNP represents a more aggressive phenotype characterized by

(c) The Author(s) 2020. This article is licensed under a Creative Commons Attribution 4.0 International License, which permits use, sharing, adaptation, distribution and reproduction in any medium or format, as long as you give appropriate credit to the original author(s) and the source, provide a link to the Creative Commons licence, and indicate if changes were made. The images or other third party material in this article are included in the article's Creative Commons licence, unless indicated otherwise in a credit line to the material. If material is not included in the article's Creative Commons licence and your intended use is not permitted by statutory regulation or exceeds the permitted use, you will need to obtain permission directly from the copyright holder. To view a copy of this licence, visit http://creativeco mmons.org/licenses/by/4.0/. The Creative Commons Public Domain Dedication waiver (http://creativecommons.org/publicdomain/ zero/1.0/) applies to the data made available in this article, unless otherwise stated in a credit line to the data. 
a higher degree of disease severity, poorer responses to therapeutic interventions and higher polyp recurrence rates after surgery [4-6].

Given that ECRSwNP and nonECRSwNP potentially exhibit different responses to therapeutic interventions, distinguishing ECRSwNP from nonECRSwNP prior to surgery may be important in guiding the options for treatment [7]. In this regard, specific biomarkers are more objective in analyzing disease phenotype and the underlying pathogenesis [8], compared with endoscopic examinations, imaging techniques, and clinical characteristics.

Arachidonate 15-lipoxygenase (ALOX15), a member of the lipoxygenase family that metabolizes arachidonic acid (AA) to 15(S)-hydroperoxy-eicosatetraenoic acid (15-(S)-HETE) [9], is mainly expressed in eosinophils, activated monocytes, epithelial cells and mast cells [10]. ALOX15 has been suggested to promote eosinophil infiltration in eosinophilic inflammatory diseases, such as aspirin-exacerbated respiratory disease [11], eosinophilic esophagitis [12], and asthma [13]. Several studies have demonstrated increased levels of ALOX15 and its metabolites in asthma [14-16], which can lead to bronchial epithelial injury and remodeling [16] and regulate goblet cell differentiation in asthmatic human airway epithelial cells [9]. More recently, we have demonstrated that the expression of ALOX15 is significantly higher in patients with ECRSwNP than in patients with nonECRSwNP and healthy controls [17].

Considering the role of ALOX15 in eosinophilic inflammation, we hypothesized that ALOX15 may be a useful biomarker for differentiating ECRSwNP from nonECRSwNP. Thus, in this study, we aimed to evaluate the potential of ALOX15 alone or in combination with other characteristics in accurately predicting a diagnosis of ECRSwNP.

\section{Methods}

\section{Subjects and tissue samples}

A total of 48 subjects were enrolled from a consecutive population of CRSwNP patients undergoing endoscopic sinus surgery at Beijing TongRen Hospital, Capital Medical University from October 2016 to December 2017. The diagnoses of CRSwNP, comorbid asthma, allergic rhinitis, and atopy were made according to our previous report [18]. The patients were further classified as either ECRSwNP $(n=30)$ or non-ECRSwNP $(n=18)$ patients, based on the percentage of polyp tissue eosinophils being $>27 \%$ or $\leq 27 \%$ of the total infiltrating cells, respectively, according to the previous study [6]. Polyp tissues from all subjects were collected as biopsy specimens or during surgery for further analyses of eosinophils and ALOX15 mRNA levels as indicated below.

None of the subjects had received steroids, antibiotics, immunotherapy or anti-leukotrienes within 4 weeks before surgery. Patients with established fungal sinusitis, immunodeficiency, cystic fibrosis, or primary ciliary dyskinesia were excluded.

This study was approved by the ethics committee of Beijing TongRen Hospital, Capital Medical University, and written informed consent was obtained from all patients prior to enrolment into the study.

\section{Symptom score}

The symptoms including nasal obstruction, rhinorrhea, olfaction, and facial pain or headache were assessed preoperatively using a visual analogue scale (VAS) ranging from 0 to 10 ( 0 represents the absence of any symptom and 10 represents the most severe symptom) as described previously [19]. The sum of these four VAS scores was calculated as total VAS symptom score.

\section{Computed tomography (CT) score}

The CT score was evaluated by preoperative CT scan using the Lund-Mackay scoring system [20]. Each sinus group and the ostiomeatal complex were assigned a numeric grade: $0=$ no abnormality, $1=$ partial opacification, and $2=$ total opacification, to provide a total CT score ranging from 0 to 24 . The maxillary sinus score (M score), anterior ethmoid sinus score (AE score), and posterior ethmoid sinus score (PE score) were used to additionally calculate $\mathrm{E}$ ( $\mathrm{AE}$ score $+\mathrm{PE}$ score) / M (M score) ratio.

\section{Endoscopy score}

The endoscopy score for nasal polyps (NPs) was calculated for each nasal cavity by nasal endoscopy as previously described [21]. Each nasal cavity was graded as follows: $0=$ no polyps; $1=$ small polyps in the middle meatus not reaching below the inferior border of the middle concha; $2=$ polyps reaching below the lower border of the middle turbinate; $3=$ large polyps reaching the lower border of the attachment of inferior turbinate or polyps medial to the middle concha; $4=$ large polyps causing almost complete congestion/obstruction of the inferior meatus. The sum of the nasal polyp scores for both sides was determined as the endoscopy score.

\section{Blood parameters}

Blood samples were collected preoperatively and used to assess the blood routine parameters as well as sIgE levels for common aeroallergens including house dust mites, molds, trees, weed and grass pollen, and animal dander. 
All sIgE levels were detected using ImmunoCAP (Phadia, Uppsala, Sweden; cut-off value, $0.35 \mathrm{kUA} / \mathrm{L}$ ).

\section{Hematoxylin and eosin (H\&E) staining}

Hematoxylin and eosin (H\&E) staining was performed as previously described [17]. The stained sections were evaluated for eosinophil infiltration by an investigator blinded to the patients' clinical characteristics, in 5 nonoverlapping high-power fields (HPF, $\times 400$ magnification) using a Leica microscope (Leica Microsystems, Bannockburn, USA).

The tissue eosinophils were expressed as a percentage of total infiltrating cells as follows

\section{Results}

Comparison of the demographic, laboratory and clinical characteristics between ECRSwNP and nonECRSwNP

Thirty CRSwNP patients (62.5\%) were classified into the eosinophilic group, and eighteen CRSwNP patients (37.5\%) were classified into non-eosinophilic group. Significant differences were noted in the levels of tissue and blood eosinophils (all $P<0.001$ ), tissue neutrophils $(P=0.003)$, olfaction scores $(P=0.002)$, total VAS scores $(P=0.021), \mathrm{E} / \mathrm{M}$ ratio $(P=0.003)$, and endoscopy scores $(P=0.003)$ between the two groups (Table 1 ). Then, ECRSwNP patients were more likely to have asthma $(P=0.003)$, allergic rhinitis $(P=0.044)$ and atopy

Tissue eosinophils $(\%)=($ number of tissue eosinophils $/ \mathrm{HPF}) \times 100 \% / \Sigma($ number of tissue eosinophils + number of tissue neutrophils + number of tissue lymphocytes + number of tissue plasma cells)/HPF.

\section{Real-time polymerase chain reaction (RT-PCR) analysis}

Reverse transcription and RT-PCR were performed to detect ALOX15 mRNA level in nasal polyp tissues as previously described [17]. Primer sequences employed for RT-PCR were as follows: ALOX15, forward primer: GGGCAAGGAGACAGAACTCAA, reverse primer: CAGCGGTAACAAGGGAACCT; GAPDH, forward primer: 5'-CTCCTCCTGTTCG- ACAGTCAGC-3', reverse primer: 5'-CCCAATACGACCAAATCCGTT$3^{\prime}$. The relative ALOX15 mRNA level was calculated according to the formula: $2^{-\Delta \mathrm{Ct}}=2^{-(\mathrm{Ct} \text { ALOX15 }-\mathrm{Ct} \text { GAPDH })}$. For statistical analysis, $2^{-\Delta \mathrm{Ct}}$ values were $\log _{2}$ (equivalent to $-\Delta \mathrm{Ct}$ ) converted into linearization, which represented that the relative level of ALOX15 mRNA was normalized to GAPDH mRNA. A higher value of $-\Delta C$ t represents a higher level of ALOX15 mRNA expression.

\section{Statistical analysis}

Statistical analysis was performed using SPSS 23.0 (IBM Corp, Armonk, USA). Values of the continuous normal distribution were presented as mean \pm standard deviation, others were expressed as median and interquar range. Continuous variable differences and unpaired comparisons were analyzed by the Student's $t$-test or Mann-Whitney $U$ test, respectively. Sex, previous surgery, asthma, allergic rhinitis and atopy were compared using Chi-square test. Correlations between ALOX15 mRNA expression and laboratory and clinical characteristics were assessed by Spearman correlation test. Binary logistic regression was used to detect potential predictors for ECRSwNP. The predictive ability of ALOX15 and other predictors was evaluated by receiver operating characteristic (ROC) curve. MedCalc statistical software (version 15.2, Ostend, Belgium) was used to compare AUC levels of the factors. $P<0.05$ was considered statistically significant.
$(P=0.034)$ (Table 1$)$, as well as higher ALOX15 mRNA levels in nasal polyp tissues $(P<0.001)$ (Fig. 1). However, the two groups were not significantly different with other characteristics (shown in Table 1).

\section{Associations between ALOX15 level and laboratory and clinical characteristics}

The level of ALOX15 mRNA was significantly correlated with tissue eosinophils $(r=0.565, P<0.001)$, olfaction scores $(r=0.400, P=0.005)$, total VAS scores $(r=0.383$, $P=0.007), E / M$ ratio $(r=0.463, P=0.001)$, endoscopy scores $(r=0.409, P=0.004)$, and blood eosinophils ( $r=0.395, P=0.006)$; but not with age, tissue neutrophils, nasal obstruction scores, rhinorrhea scores, facial pain or headache scores, CT scores, or blood neutrophils (shown in Table 2).

\section{Assessment of the predictive value of the ALOX15 mRNA for ECRSwNP}

To determine the predictive value of the ALOX15 mRNA for ECRSwNP, binary logistic regression analysis was conducted. Blood eosinophils, which has been shown to predict ECRSwNP previously [18], has also been introduced. The regression indicated that both ALOX15 mRNA $(\mathrm{OR}=4.440,95 \% \mathrm{CI}=1.614-12.213, P=0.004)$ and blood eosinophils ( $\mathrm{OR}=1.457,95 \% \mathrm{CI}=1.024-$ $2.074, P=0.036)$ showed the potential in predicting ECRSwNP (Table 3), and were thus, further subjected to ROC analysis.

ROC curve analysis showed that ALOX15 mRNA had a high accuracy, and blood eosinophils a moderate accuracy as predictors of ECRSwNP (AUC $=0.909$, 95\% $\mathrm{CI}=0.828-0.990, \quad P<0.001 ; \quad$ and $\mathrm{AUC}=0.820$, 95\% CI $=0.687-0.954, P<0.001$, respectively) (Fig. 2). A maximal Youden index value of 0.700 demonstrated a cut-off value of -2.113 for ALOX15 to predict the diagnosis of ECRSwNP with a sensitivity of $83.3 \%$ and a 
Table 1 Baseline characteristics of patients

\begin{tabular}{|c|c|c|c|}
\hline & ECRSwNP $(n=30)$ & NonECRSwNP $(n=18)$ & $P$ value \\
\hline \multicolumn{4}{|l|}{ Demographic characteristics } \\
\hline Sex, male/female & $17 / 13$ & $11 / 7$ & 0.762 \\
\hline Age, y (mean $\pm S D)$ & $45.03 \pm 11.86$ & $46.00 \pm 15.77$ & 0.810 \\
\hline Previous surgery, n (\%) & $10(33.33)$ & $7(38.89)$ & 0.697 \\
\hline Asthma, n (\%) & $16(53.33)$ & $2(11.11)$ & 0.003 \\
\hline Allergic rhinitis, n (\%) & $9(30.00)$ & $1(5.56)$ & 0.044 \\
\hline Atopy, n (\%) & $16(53.33)$ & $4(22.22)$ & 0.034 \\
\hline \multicolumn{4}{|l|}{ Histopathological findings (H\&E staining) } \\
\hline Tissue eosinophils (\%), median (IQR) & $57.27(41.86-68.43)$ & $4.19(1.97-6.68)$ & $<0.001$ \\
\hline Tissue neutrophils (\%), median (IQR) & $0.00(0.00-2.18)$ & $6.84(2.53-13.39)$ & 0.003 \\
\hline \multicolumn{4}{|l|}{ Self-assessed symptom scores (VAS) } \\
\hline Nasal obstruction score, median (IQR) & $7.00(6.00-8.00)$ & $6.00(6.00-8.00)$ & 0.572 \\
\hline Rhinorrhea score, median (IQR) & $6.00(5.00-7.00)$ & $5.50(0.00-6.00)$ & 0.078 \\
\hline Olfaction score, median (IQR) & $9.00(6.00-10.00)$ & $6.00(4.00-8.00)$ & 0.002 \\
\hline Facial pain or headache score, median (IQR) & $0.00(0.00-5.00)$ & $0.00(0.00-5.25)$ & 0.581 \\
\hline Total VAS score, median (IQR) & $22.50(19.00-25.50)$ & $19.50(16.75-22.25)$ & 0.021 \\
\hline \multicolumn{4}{|l|}{ Imaging examination scores } \\
\hline CT score, median (IQR) & $17.50(14.00-22.00)$ & $17.50(11.00-20.25)$ & 0.326 \\
\hline E/M ratio, median (IQR) & $2.33(2.00-3.50)$ & $2.00(2.00-2.00)$ & 0.003 \\
\hline Endoscopy score, median (IQR) & $5.50(4.00-7.00)$ & $4.00(2.75-5.00)$ & 0.003 \\
\hline \multicolumn{4}{|l|}{ Routine blood tests } \\
\hline Blood eosinophils (\%), median (IQR) & $6.25(5.05-9.20)$ & $1.60(0.78-4.95)$ & $<0.001$ \\
\hline Blood neutrophils (\%), median (IQR) & $53.45(47.03-56.68)$ & $58.50(48.18-69.75)$ & 0.058 \\
\hline
\end{tabular}

ECRSWNP eosinophilic chronic rhinosinusitis with nasal polyps, nonECRSWNP non-eosinophilic chronic rhinosinusitis with nasal polyps, y years, SD standard deviation, $n$ number, $H \& E$ hematoxylin and eosin, IQR interquartile range, VAS visual analogue scale, CT computed tomography, E/M ethmoid/maxillary sinus. Italic values are significant at $P<0.05$

specificity of $86.7 \%$ (Fig. 2). Similarly, a maximal Youden index value of 0.656 demonstrated a cut-off point of $3.45 \%$ for blood eosinophils in predicting the diagnosis of ECRSwNP with a sensitivity of $72.2 \%$ and a specificity of 93.3\% (Fig. 2).

In view of the slightly lower accuracy and sensitivity of blood eosinophils in predicting ECRSwNP, we speculated that a combination of ALOX15 and blood eosinophils might improve the value of blood eosinophils in predicting ECRSwNP. A model comprising these combined predictors, derived from logistic regression analysis, was thus established as follows:

Model $=$ ALOX15 mRNA level $(-\Delta \mathrm{Ct}$ value $)+$ blood eosinophils $(\%) \times 37.7 / 1.491$.

ROC curve analysis of the combined data for ALOX15 and blood eosinophils indicated an increased AUC of 0.933 ; with a cut-off value of -0.778 and sensitivity of $83.3 \%$ and specificity of $90.0 \%$; which were improvements over the accuracy and sensitivity of blood eosinophils, as well as the specificity of ALOX15 mRNA. Although the AUC for the combination of ALOX15 and blood eosinophils was not significantly different from the AUC of ALOX15 mRNA $(P=0.363)$ alone, this was statistically different from the AUC of blood eosinophils $(P=0.028)$; indicating a higher value of the combination of ALOX15 mRNA and blood eosinophils in predicting ECRSwNP, than the value of blood eosinophils alone.

\section{Comparisons of the laboratory and clinical characteristics between the high- and the low-combination level group} Based on the optimal cut-off value of -0.778 for the combination of ALOX15 mRNA and blood eosinophils, the CRSwNP patients were divided into a high combination level group (values $\geq-0.778, \mathrm{n}=30$ ) and a low combination level group (values $<-0.778, \mathrm{n}=18$ ). The occurrence of ECRSwNP was significantly higher in the high combination level group $(n=27)$ than in the low combination level group $(n=3)(P<0.001)$ (Fig. 3a).

Comparison of the demographic and clinical characteristics of the two groups demonstrated that the combined level was not significantly associated with the distribution of sex, age, previous surgery (Fig. 3b-d). However, patients in the high combination level group were more likely to suffer from asthma $(P=0.021)$, allergic rhinitis $(P=0.044)$, and atopy $(P=0.020)$ (Fig. 3eg). Moreover, patients with high combination levels 

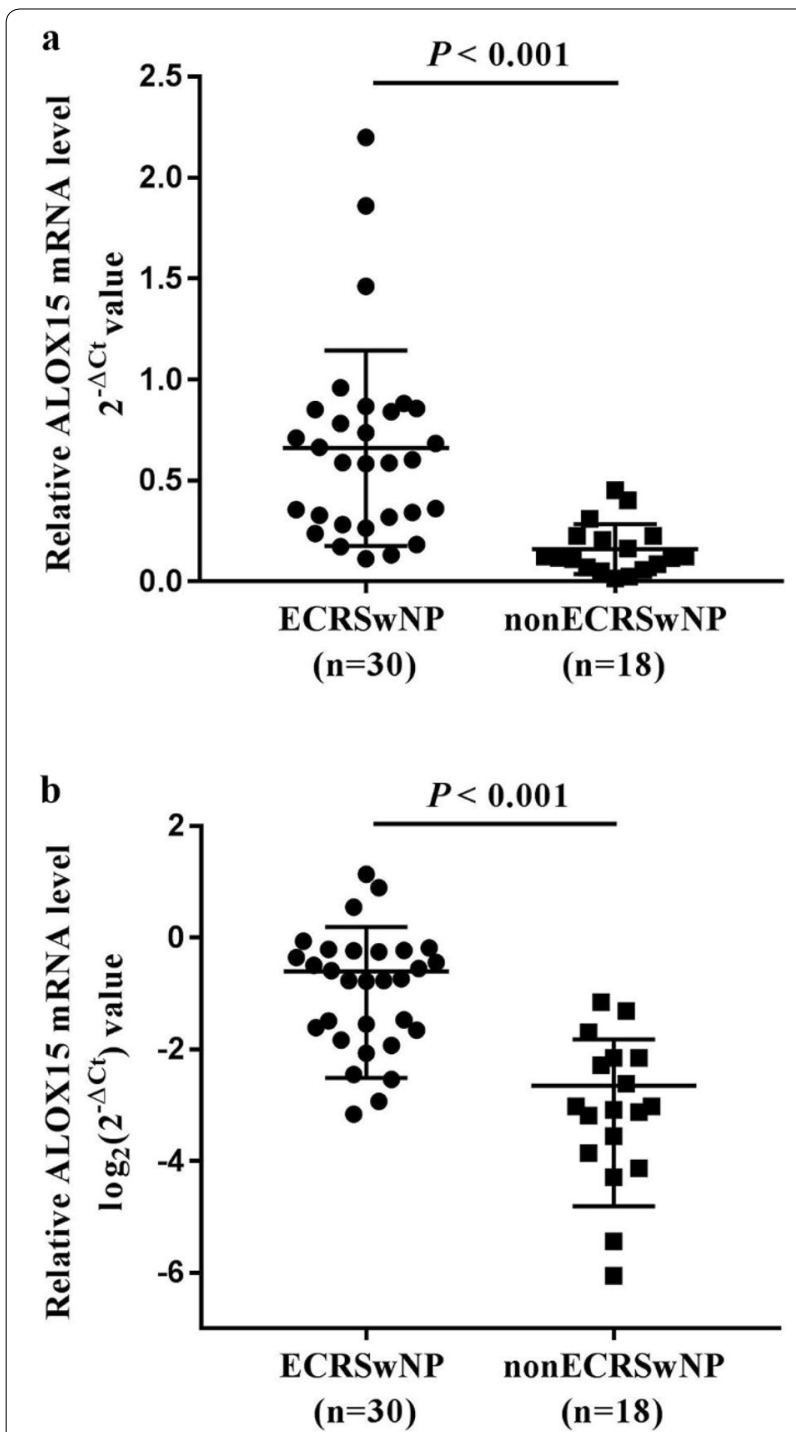

Fig. 1 Relative expression of ALOX15 mRNA levels in nasal mucosa tissues of ECRSWNP and nonECRSWNP determined by RT-PCR. a The relative expression level of ALOX15 mRNA was determined by $2^{-\Delta C t}$ value. $\mathbf{b}$ The relative mRNA level of ALOX15, which corresponded to the level of $-\Delta C t$, was analyzed by $\log _{2}\left(2^{-\Delta C t}\right)$ methods. A higher $-\Delta C t$ value represents a higher ALOX15 mRNA level. ALOX15 arachidonate 15-lipoxygenase, ECRSWNP eosinophilic chronic rhinosinusitis with nasal polyps, nonECRSWNP non-eosinophilic chronic rhinosinusitis with nasal polyps, $R T-P C R$ real-time polymerase chain reaction

showed significantly higher ALOX15 mRNA levels and higher eosinophil, but not neutrophil infiltration, in both polyp tissue and peripheral blood than patients with low combination levels (all $P<0.001$ ) (Fig. 4). Assessment of self-assessed symptom scores demonstrated that rhinorrhea scores $(P=0.042)$, olfaction scores $(P=0.007)$, and total VAS scores $(P=0.003)$ were significantly higher in patients with high combination levels (Fig. 5). Similarly,
Table 2 Spearman correlations between ALOX15 mRNA level and laboratory and clinical characteristics

\begin{tabular}{llrr}
\hline Correlation & & $\boldsymbol{r}$ value & $\boldsymbol{P}$ value \\
\hline ALOX15 mRNA & Age & -0.116 & 0.433 \\
level (- $\triangle \mathrm{Ct}$ & Tissue eosinophils (\%) & 0.565 & $<0.001$ \\
value) & Tissue neutrophils (\%) & -0.167 & 0.256 \\
& Nasal obstruction score & 0.149 & 0.312 \\
& Rhinorrhea score & 0.225 & 0.124 \\
& Olfaction score & 0.400 & 0.005 \\
& Facial pain or headache score & 0.056 & 0.706 \\
& Total VAS score & 0.383 & 0.007 \\
& CT score & 0.150 & 0.309 \\
& E/M ratio & 0.463 & 0.001 \\
& Endoscopy score & 0.409 & 0.004 \\
& Blood eosinophils (\%) & 0.395 & 0.006 \\
& Blood neutrophils (\%) & -0.159 & 0.280 \\
\hline
\end{tabular}

ALOX15 arachidonate 15-lipoxygenase, VAS visual analogue scale, CT computed tomography, E/M ethmoid/maxillary sinus. Italic values are significant at $P<0.05$

Table 3 Binary logistic regression analysis for potential factors predicting ECRSwNP

\begin{tabular}{llll}
\hline Factors & OR & $\mathbf{9 5 \% ~ C l}$ & $\boldsymbol{P}$ value \\
\hline ALOX15 (- $\triangle$ Ct value) & 4.440 & $1.614-12.213$ & 0.004 \\
Blood eosinophils (\%) & 1.457 & $1.024-2.074$ & 0.036 \\
\hline
\end{tabular}

ECRSWNP eosinophilic chronic rhinosinusitis with nasal polyps, OR odds ratio, $\mathrm{Cl}$ confidence interval, ALOX15 arachidonate 15-lipoxygenase

analysis of imaging examination scores indicated that E/M ratio $(P=0.032)$ and endoscopy scores $(P=0.001)$, but not $\mathrm{CT}$ scores, were significantly higher in patients with high combination levels (Fig. 6).

\section{Discussion}

Compared with nonECRSwNP, ECRSwNP has a closer relationship to airway disease such as asthma with broader eosinophilic airway inflammation [22, 23], and tends to have higher incidence rates of asthma and allergic rhinitis [24-26]. Indeed, our findings for the higher incidence rates for asthma, allergic rhinitis and atopy in ECRSwNP patients compared with nonECRSwNP patients in the present study are consistent with the findings of these earlier studies. Then, as patients with ECRSwNP have a greater chance of relapse after surgery, increased rates of postsurgical medication, and poorer quality of life than patients with non-eosinophilic or neutrophilic phenotypes $[5,6$, 27-30]. Thus, to distinguish CRSwNP as eosinophilic or non-eosinophilic CRSwNP is likely to be important for formulating individualized treatment plans, predicting the prognosis, and reducing recurrence. 


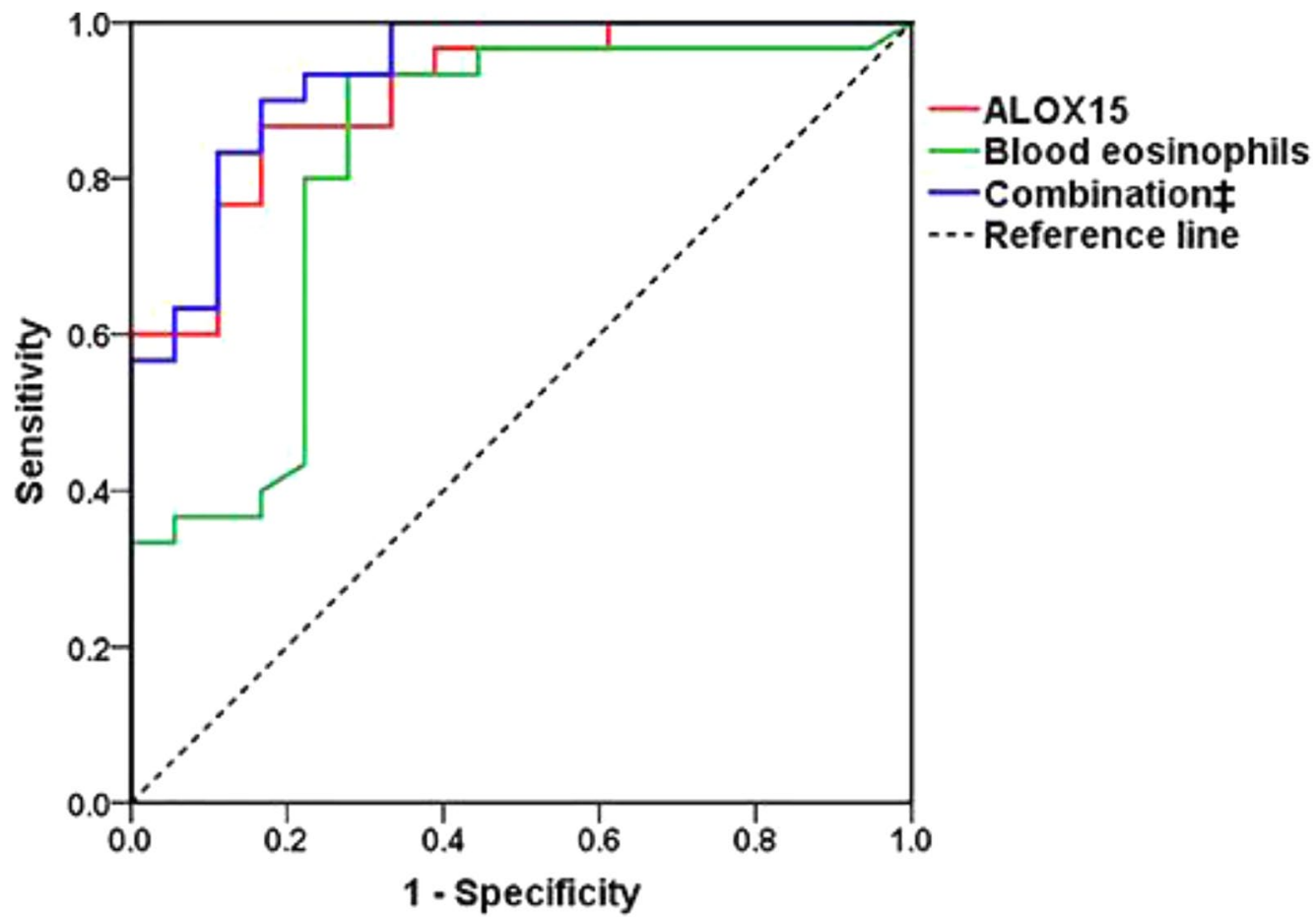

Fig. 2 ROC curves of ALOX15, blood eosinophils, and their combination for predicting the diagnosis of ECRSwNP. The predictive ability was calculated according to AUC. ALOX15 alone and in combination with blood eosinophils demonstrated high accuracies, and blood eosinophils alone moderate accuracy in predicting ECRSWNP (AUC: 0.909, 0.933, and 0.820, respectively). ROC receiver operator characteristic, ALOX 15 arachidonate 15-lipoxygenase, ECRSWNP eosinophilic chronic rhinosinusitis with nasal polyps, AUC area under the curve. \#: combined ALOX15 with blood eosinophils

Currently, several clinical characteristics such as tissue eosinophils [1, 6], blood eosinophils [31], E/M ratio [24], and the Japanese Epidemiological Survey of Refractory Eosinophilic Chronic Rhinosinusitis (JESREC) [32] scores are used to identify ECRSwNP. In the present study, we evaluated the significance of clinical characteristics to differentiate between ECRSwNP and nonECRSwNP. In accordance with findings from other studies [32-34], our study also showed significant differences between the two sub-phenotypes, with respect to symptom scores, E/M ratio, endoscopy scores and blood eosinophils.

Unlike clinical characteristics, biomarkers are considered to be more objective indicators in evaluating ECRSwNP. Some studies have shown Charcot-Leyden crystals (CLCs) to be a marker of eosinophils [35, 36], and studies from our group have demonstrated CLCs to be a predictor of ECRSwNP [18, 37]. Unlike CLCs, ALOX15 as a metabolic enzyme, which together with its metabolites plays an important role in eosinophilic inflammation and influences epithelial cell function at a local metabolic level $[9,13,15,17,38-45]$. More recently, a genome-wide association study involving nearly 10,000 NP and CRS patients and over 70,000 controls has indicated a missense variant in ALOX15 that causes alteration in enzymatic activity and confers large genome-wide significant protection against NP [46]. In our study, we found that ALOX15 mRNA level was significantly increased in ECRSwNP patients compared with nonECRSwNP patients and positively associated with tissue eosinophils, olfaction scores,

(See figure on next page.)

Fig. 3 Comparison of the demographic characteristics between the high combination level group and the low combination level group, divided according to the predictive cut-off value. a number of ECRSwNP patients (black columns) / nonECRSwNP patients (grey columns), $\mathbf{b}$ sex (black columns for female, grey columns for male), c age, $\mathbf{d}$ previous surgery, e comorbid asthma, $\mathbf{f}$ comorbid allergic rhinitis, and $\mathbf{g}$ comorbid atopy (d-g, black columns for yes and grey columns for no for other characteristics). ECRSWNP eosinophilic chronic rhinosinusitis with nasal polyps, nonECRSWNP non-eosinophilic chronic rhinosinusitis with nasal polyps. The combination represents arachidonate 15-lipoxygenase with blood eosinophils 


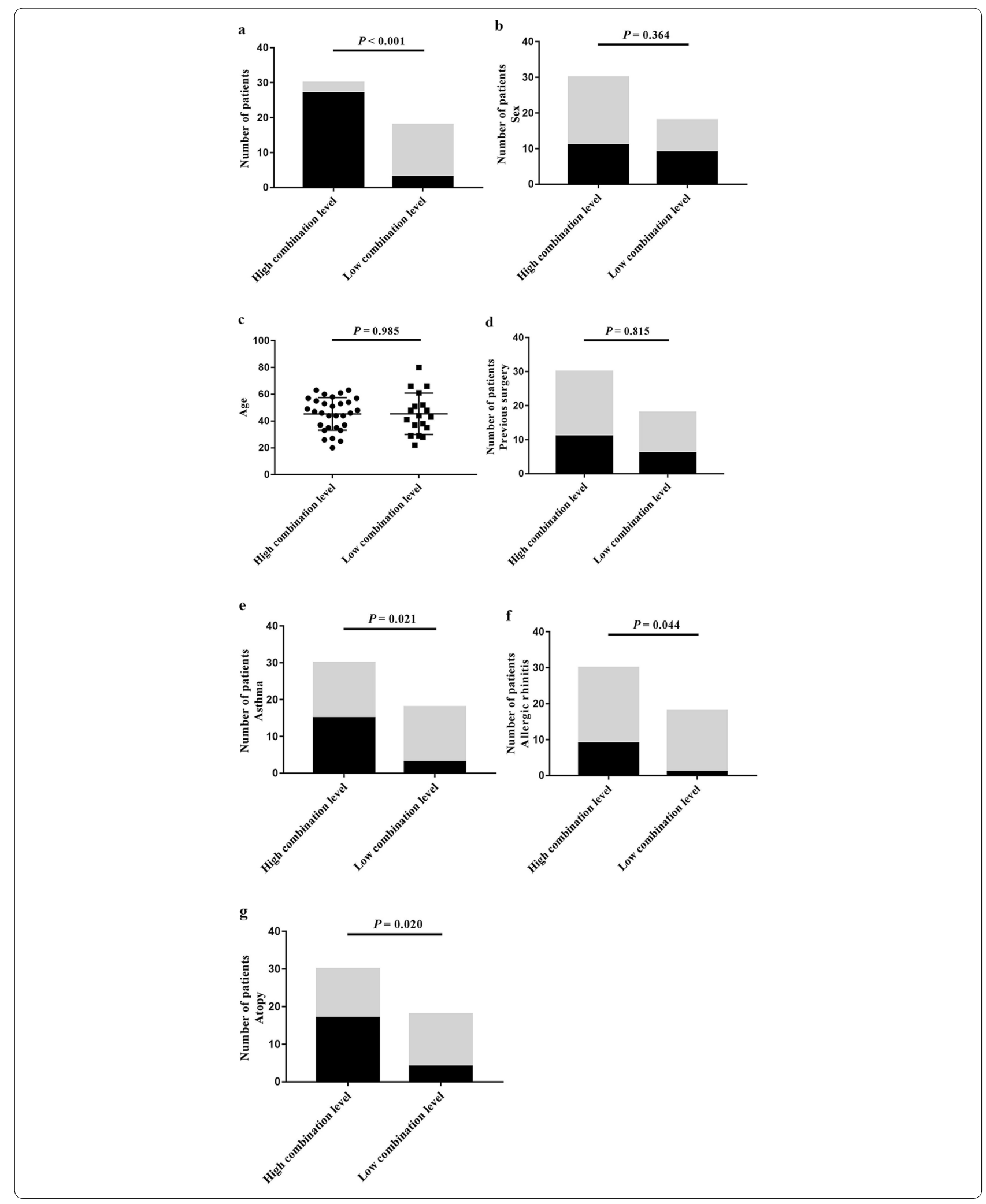



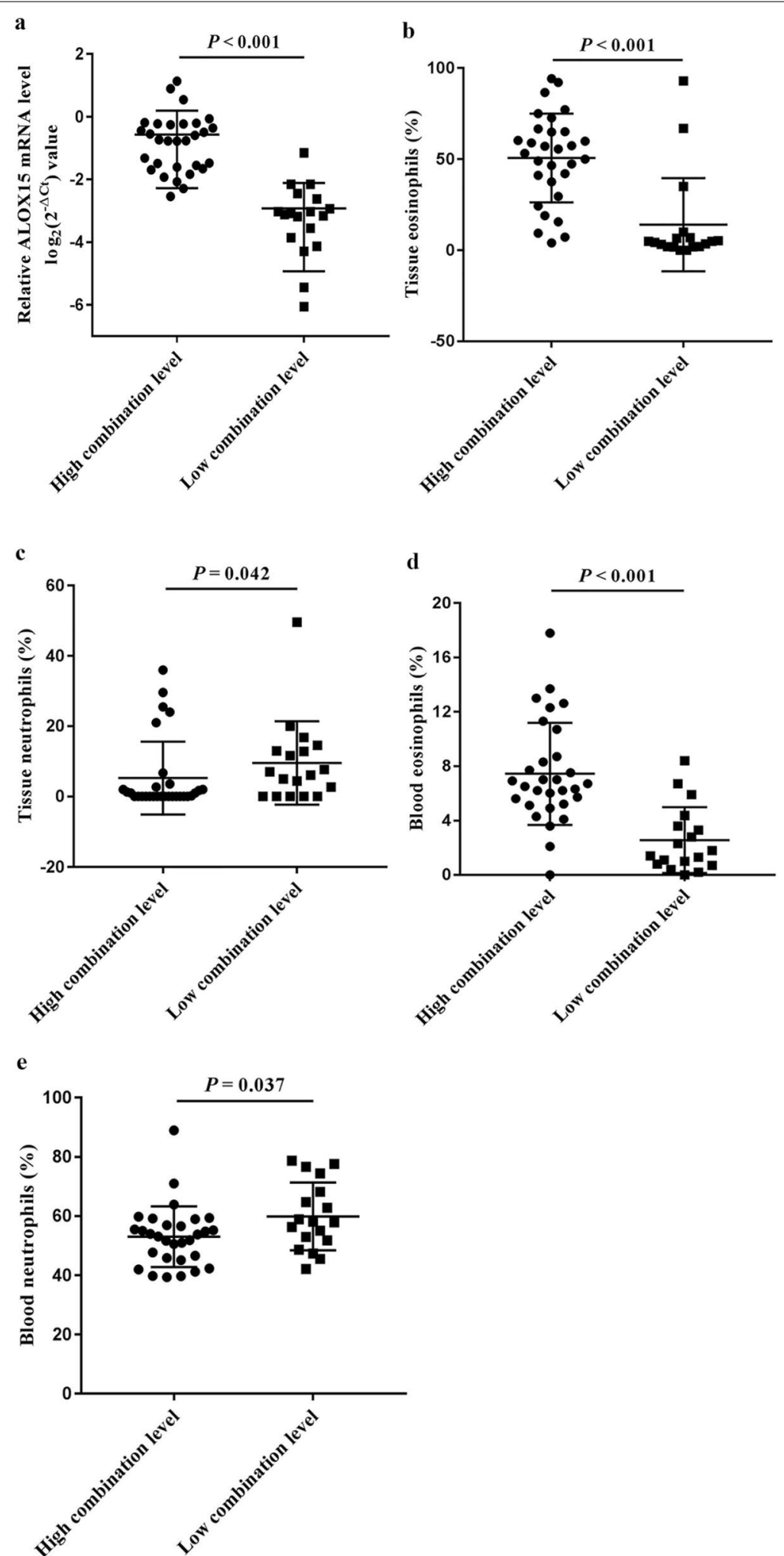

Fig. 4 Infiltration of inflammatory cells in nasal polyp tissues and peripheral blood, and ALOX15 mRNA level in CRSwNP patients with the combination level greater than or less than the predictive cut-off value. a ALOX15 mRNA (- $\triangle$ Ct value), $\mathbf{b}$ tissue eosinophils, $\mathbf{c}$ tissue neutrophils, d blood eosinophils, and e blood neutrophils. ALOX15 arachidonate 15-lipoxygenase, CRSWNP chronic rhinosinusitis with nasal polyps. The combination represents arachidonate 15-lipoxygenase with blood eosinophils 

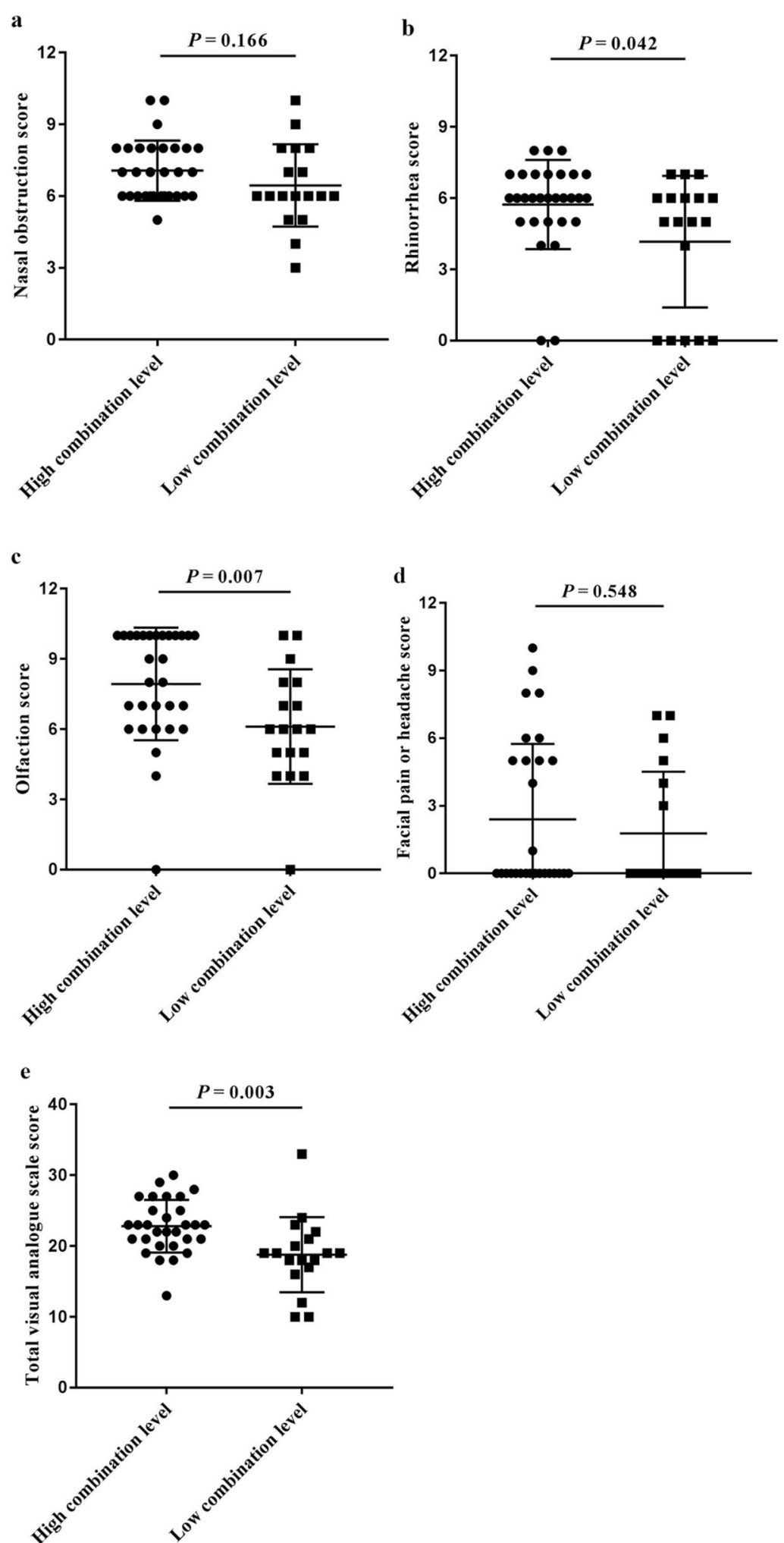

Fig. 5 Comparison of self-assessed symptom scores (VAS) between the high combination level group and the low combination level group divided according to the predictive cut-off value. a nasal obstruction score, $\mathbf{b}$ rhinorrhea score, $\mathbf{c}$ olfaction score, $\mathbf{d}$ facial pain or headache score, and $\mathbf{e}$ total VAS score. VAS visual analogue scale. The combination represents arachidonate 15 -lipoxygenase with blood eosinophils 

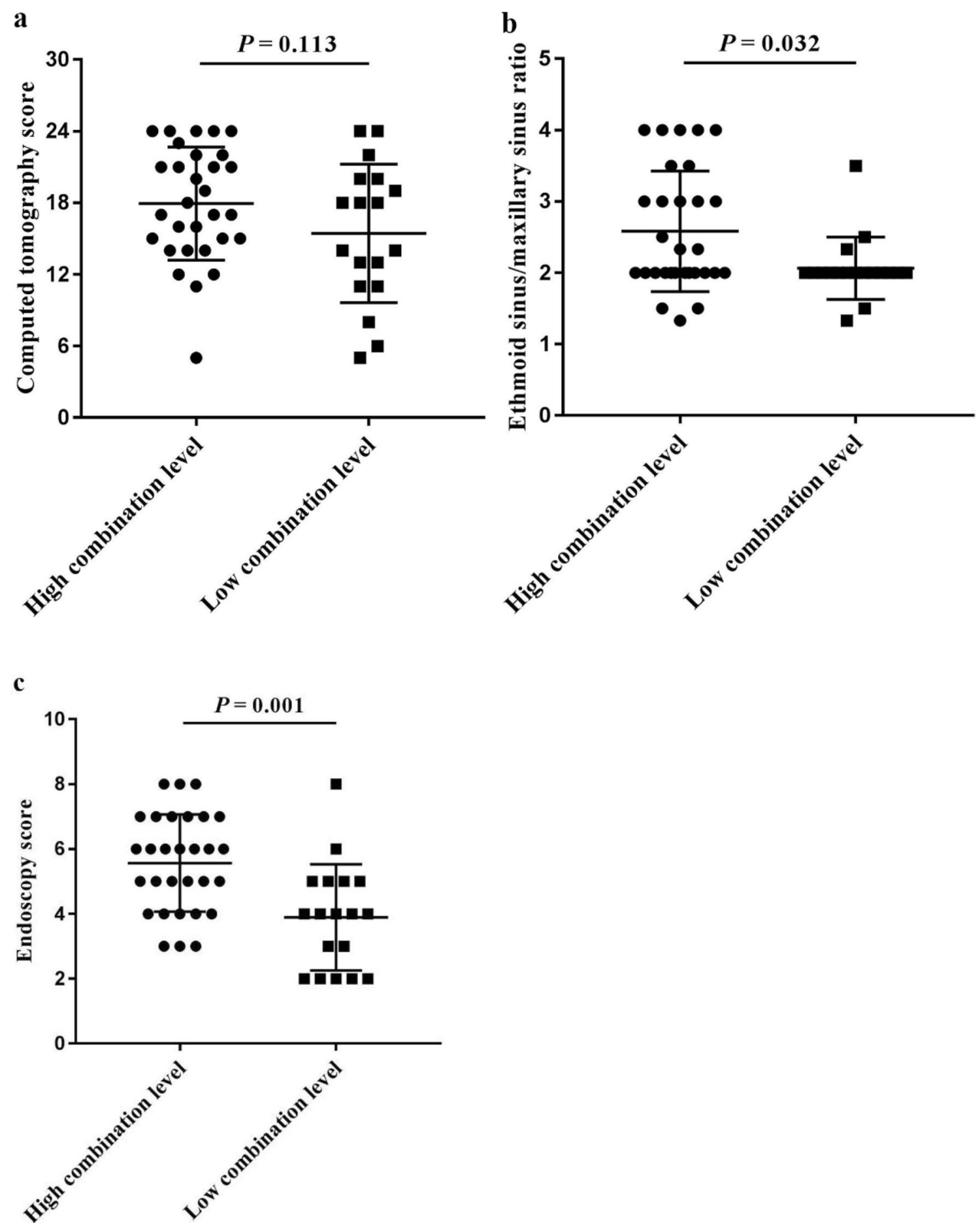

Fig. 6 Comparison of the imaging examination scores between the high combination level group and the low combination level group divided according to the predictive cut-off value. a CT score, $\mathbf{b}$ E/M ratio, and $\mathbf{c}$ Endoscopy score. CT computed tomography, E/M ethmoid/maxillary sinus. The combination represents arachidonate 15-lipoxygenase with blood eosinophils

total VAS scores, E/M ratio, endoscopy scores, and blood eosinophils; suggesting that ALOX15 might have predictive significance for ECRSwNP.
Indeed, analysis of ALOX15 mRNA and blood eosinophils by a binary logistic regression model and ROC curve analysis, suggested that ALOX15 might be 
a valuable predictor of ECRSwNP as shown by high accuracy, whereas by comparison, blood eosinophils had lower accuracy in predicting ECRSwNP. Moreover, the finding that combination of ALOX15 mRNA and blood eosinophils could improve the accuracy and sensitivity of blood eosinophils in predicting for ECRSwNP indicates that combining the two factors has an optimal predictive value for ECRSwNP. These results also suggest that if patients with ECRSwNP present with both ALOX15 >-2.113 and blood eosinophils $>3.45 \%$, then greater attention needs to be paid to these patients and more active and effective treatment measures need to be implemented for these patients in clinical practice.

Furthermore, analysis of ECRSwNP patients based on the optimal cut-off value of -0.778 for the combination of ALOX15 mRNA and blood eosinophils, the CRSwNP patients with values $\geq-0.778$ (high combination group) had significantly higher comorbid asthma, allergic rhinitis, atopy, rhinorrhea scores, olfaction scores, total VAS scores, E/M ratio, endoscopy scores, and blood eosinophils compared with CRSwNP patients with values $<-0.778$ (low combination group), which were basically consistent with the results of ECRSwNP group mentioned above. As eosinophilic CRS (ECRS) shares many histologic and immunologic features with asthma, it is possible that ECRS and asthma may be influenced by the same immune processes in the upper and lower airways [47-49]. The findings of the present study also support this view and suggest that ALOX15 probably plays an important pathophysiologic role in both the upper and lower airways. Thus, according to the concept of "one airway, one disease", patients with both ECRSwNP and asthma with increased ALOX15 expression in polyp tissues, would likely benefit from treatment for both diseases.

However, our study has some limitations, including the relatively small sample size and the role of ALOX15 in ECRSwNP was assessed only by determining the ALOX15 mRNA level. Moreover, only a preliminary inference has been made that ALOX15 might play a role in the upper and lower airways involving ECRSwNP and asthma. Therefore, large study sample size is necessary to further verify the predictive value of ALOX15 for ECRSwNP, and to validate the role of ALOX15 in ECRSwNP from multiple levels. In addition, the specific mechanism of ALOX15 in the upper and lower airway inflammation needs to be further studied in the future.

\section{Conclusions}

In conclusion, the present study showed that the expression of ALOX15 was significantly upregulated in ECRSwNP patients, compared with nonECRSwNP patients. Furthermore, the level of ALOX15 mRNA expression was correlated with the numbers of tissue and blood eosinophils, olfaction scores, facial pain or headache scores, total VAS scores, E/M ratio, and endoscopy scores; and additionally exhibited a high accuracy for predicting ECRSwNP. Overall, these findings suggest that ALOX15 might be a reliable biomarker for differentiating ECRSwNP patients from nonECRSwNP patients and thus provide a new intervention target for the clinical treatment of ECRSwNP as well be important in guiding future treatment strategies for these patients.

\section{Abbreviations \\ ECRSwNP: Eosinophilic chronic rhinosinusitis with nasal polyps; NonECRSwNP: Non-eosinophilic chronic rhinosinusitis with nasal polyps; ALOX15: Arachidonate 15-lipoxygenase; CRSwNP: Chronic rhinosinusitis with nasal polyps; RT-PCR: Real-time polymerase chain reaction; ROC: Receiver operating characteristic; VAS: Visual analogue scale; E/M: Ethmoid/maxillary sinus; AUC : Area under the curve; AA: Arachidonic acid; 15-(S)-HETE: 15(S)-hydroperoxy- eicosatetraenoic acid; N: Number; CT: Computed tomography; M score: Maxillary sinus score; AE score: Anterior ethmoid sinus score; PE score: Posterior ethmoid sinus score; NPs: Nasal polyps; H\&E: Hematoxylin and eosin; HPF: High-power fields; Cl: Confidence interval; JESREC: Japanese Epidemiological Survey of Refractory Eosinophilic Chronic Rhinosinusitis; CLCs: Charcot-Leyden crystals; ECRS: Eosinophilic chronic rhinosinusitis; Y: Years; SD: Standard deviation; IQR: Interquartile range; OR: Odds ratio.}

\section{Acknowledgements}

We thank Yang Wang for her guidance on our experiment.

\section{Authors' contributions}

$\mathrm{ZL}$ and BY contributed to the design of the study, analysis of data and the drafting of the article. CL and RT participated in the collection of clinical samples and experimental data. CW and LZ designed the study, enrolled the patients, and made critical revisions of the article for important intellectual content. All authors read and approved the final manuscript.

\section{Funding}

This study was supported by grants from the National Natural Science Foundation of China (81870698, 81420108009, 81400444, 81470678 and 81630023), CAMS Innovation Fund for Medical Sciences (2019-12M5-022), the National Key R\&D Program of China (2018YFC0116801 and 2016YFC20160905200), the program for Changjiang Scholars and Innovative Research Team (IRT13082), Beijing Municipal Administration of Hospitals' Innovation Program of Clinical Techniques (XMLX201816), the Priming Scientific Research Foundation for the Senior Researcher in Beijing TongRen Hospital, Capital Medical University (2017-YJJ-GGL-005), Beijing Municipal Administration of Hospitals incubating Program (PX20190007), Beijing Natural Science Foundation (7194247), Public Welfare Development and Reform Pilot Project (2019-10), and Beijing Scientific and Technological Overall Plan (Z171100000117002).

\section{Availability of data and materials}

The datasets used and/or analyzed during the current study are available from the corresponding author on reasonable request.

\section{Ethics approval and consent to participate}

This study was approved by the ethics committee of Beijing TongRen Hospital, Capital Medical University, and written informed consent was obtained from all patients prior to enrollment into the study.

\section{Consent for publication}

Not applicable.

Competing interests

The authors declare that they have no competing interests. 


\section{Author details}

${ }^{1}$ Department of Otolaryngology, Head and Neck Surgery, Beijing TongRen Hospital, Capital Medical University, Beijing 100730, People's Republic of China.

2 Beijing Key Laboratory of Nasal Diseases, Beijing Institute of Otolaryngology, Beijing 100005, People's Republic of China. ${ }^{3}$ Department of Allergy, Beijing TongRen Hospital, Capital Medical University, Beijing 100730, People's Republic of China. ${ }^{4}$ Research Unit of Diagnosis and Treatment of Chronic Nasal Diseases, Chinese Academy of Medical Sciences, Beijing 100005, People's Republic of China.

Received: 29 May 2020 Accepted: 4 September 2020

Published online: 16 September 2020

\section{References}

1. Cao PP, Li HB, Wang BF, Wang SB, You XJ, Cui YH, et al. Distinct immunopathologic characteristics of various types of chronic rhinosinusitis in adult Chinese. J Allergy Clin Immunol. 2009;124:478-84

2. Kato A. Immunopathology of chronic rhinosinusitis. Allergol Int 2015;64:121-30.

3. Chen $\mathrm{K}$, Han M, Tang M, Xie Y, Lai Y, Hu X, et al. Differential Hrd1 expression and B-cell accumulation in eosinophilic and non-eosinophilic chronic rhinosinusitis with nasal polyps. Allergy Asthma Immunol Res. 2018;10:698-715

4. Wei Y, Xia W, Ye X, Fan Y, Shi J, Wen W, et al. The antimicrobial protein short palate, lung, and nasal epithelium clone 1 (SPLUNC1) is differentially modulated in eosinophilic and noneosinophilic chronic rhinosinusitis with nasal polyps. J Allergy Clin Immunol. 2014;133:420-8.

5. Grgić MV, Ćupić H, Kalogjera L, Baudoin T. Surgical treatment for nasal polyposis: predictors of outcome. Eur Arch Otorhinolaryngol. 2015;272:3735-43.

6. Lou H, Meng Y, Piao Y, Wang C, Zhang L, Bachert C. Predictive significance of tissue eosinophilia for nasal polyp recurrence in the Chinese population. Am J Rhinol Allergy. 2015;29:350-6.

7. Xu M, Zhang W, Chen D, Zhou H, Chen L. Diagnostic significance of serum periostin in eosinophilic chronic sinusitis with nasal polyps. Acta Otolaryngol. 2018;138:387-91.

8. Taylor DR. Using biomarkers in the assessment of airways disease. J Allergy Clin Immunol. 2011;128:927-34.

9. Zhao J, Minami Y, Etling E, Coleman JM, Lauder SN, Tyrrell V, et al. Preferential generation of 15-HETE-PE induced by IL-13 regulates goblet cell differentiation in human airway epithelial cells. Am J Respir Cell Mol Biol. 2017;57:692-701

10. Claesson HE, Griffiths WJ, Brunnström A, Schain F, Andersson E, Feltenmark S, et al. Hodgkin Reed-Sternberg cells express 15-lipoxygenase-1 and are putative producers of eoxins in vivo: novel insight into the inflammatory features of classical Hodgkin lymphoma. FEBS J. 2008;275:4222-344.

11. Song YS, Yang EM, Kim SH, Jin HJ, Park HS. Effect of genetic polymorphism of ALOX15 on aspirin-exacerbated respiratory disease. Int Arch Allergy Immunol. 2012;159:157-61.

12. Matoso A, Allen D, Herzlinger M, Ferreira J, Chen S, Lu S, et al. Correlation of ALOX15 expression with eosinophilic or reflux esophagitis in a cohort of pediatric patients with esophageal eosinophilia. Hum Pathol. 2014; 45:1205-12.

13. Chu HW, Balzar S, Westcott JY, Trudeau JB, Sun Y, Conrad DJ, et al. Expression and activation of 15-lipoxygenase pathway in severe asthma: relationship to eosinophilic phenotype and collagen deposition. Clin Exp Allergy. 2002;32:1558-655.

14. Zhang NZ, Chen XJ, Mu YH, Wang H. Identification of differentially expressed genes in childhood asthma. Medicine (Baltimore). 2018;97:e10861

15. James A, Daham K, Backman L, Brunnström A, Tingvall T, Kumlin M, et al. The influence of aspirin on release of eoxin C4, leukotriene C4 and 15-HETE, in eosinophilic granulocytes isolated from patients with asthma. Int Arch Allergy Immunol. 2013;162:135-42.

16. Mabalirajan U, Rehman $R$, Ahmad T, Kumar $S$, Leishangthem GD, Singh $S$, et al. 12/15-lipoxygenase expressed in non-epithelial cells causes airway epithelial injury in asthma. Sci Rep. 2013;3:1540.
17. Yan B, Wang Y, Li Y, Wang C, Zhang L. Inhibition of arachidonate 15-lipoxygenase reduces the epithelial-mesenchymal transition in eosinophilic chronic rhinosinusitis with nasal polyps. Int Forum Allergy Rhinol. 2019;9:270-80.

18. Liu C, Yan B, Qi S, Zhang Y, Zhang L, Wang C. Predictive significance of Charcot-Leyden crystals for eosinophilic chronic rhinosinusitis with nasal polyps. Am J Rhinol Allergy. 2019;33:671-80.

19. Fokkens WJ, Lund VJ, Mullol J, Bachert C, Alobid I, Baroody F, et al. EPOS 2012: European position paper on rhinosinusitis and nasal polyps $2012 \mathrm{~A}$ summary for otorhinolaryngologists. Rhinology. 2012;50:1-12.

20. Hopkins C, Browne JP, Slack R, Lund V, Brown P. The Lund-Mackay staging system for chronic rhinosinusitis: how is it used and what does it predict? Otolaryngol Head Neck Surg. 2007;137:555-61.

21. Lu H, Lin XS, Yao DM, Zhuang YY, Wen GF, Shi J, et al. Increased serum amyloid A in nasal polyps is associated with systemic corticosteroid insensitivity in patients with chronic rhinosinusitis with nasal polyps: a pilot study. Eur Arch Otorhinolaryngol. 2018;275:401-8.

22. Snidvongs K, Chin D, Sacks R, Earls P, Harvey RJ. Eosinophilic rhinosinusitis is not a disease of ostiomeatal occlusion. Laryngoscope. 2013;123:1070-4.

23. Chandra RK, Pearlman A, Conley DB, Kern RC, Chang D. Significance of osteomeatal complex obstruction. J Otolaryngol Head Neck Surg. 2010;39:171-4

24. Meng Y, Lou H, Wang C, Zhang L. Predictive significance of computed tomography in eosinophilic chronic rhinosinusitis with nasal polyps. Int Forum Allergy Rhinol. 2016;6:812-9.

25. Sakuma Y, Ishitoya J, Komatsu M, Shiono O, Hirama M, Yamashita Y, et al. New clinical diagnostic criteria for eosinophilic chronic rhinosinusitis. Auris Nasus Larynx. 2011;38:583-8.

26. Wu D, Li L, Zhang M, Wang J, Wei Y. Two inflammatory phenotypes of nasal polyps and comorbid asthma. Ann Allergy Asthma Immunol. 2017;118:318-25

27. Wen W, Liu W, Zhang L, Bai J, Fan Y, Xia W, et al. Increased neutrophilia in nasal polyps reduces the response to oral corticosteroid therapy. J Allergy Clin Immunol. 2012;129(1522-8):e1525.

28. Brescia G, Parrino D, Zanotti C, Tealdo G, Barion U, Sfriso P, et al. Blood eosinophil and basophil values before and after surgery for eosinophilictype sinonasal polyps. Am J Rhinol Allergy. 2018;32:194-201.

29. Bassiouni A, Ou J, Rajiv S, Cantero D, Vreugde S, Wormald PJ. Subepithelial inflammatory load and basement membrane thickening in refractory chronic rhinosinusitis with nasal polyposis: a histopathological study. Int Forum Allergy Rhinol. 2016;6:248-55.

30. Vlaminck S, Vauterin T, Hellings PW, Jorissen M, Acke F, Van Cauwenberge $P$, et al. The importance of local eosinophilia in the surgical outcome of chronic rhinosinusitis: a 3-year prospective observational study. Am J Rhinol Allergy. 2014;28:260-4.

31. Ho J, Hamizan AW, Alvarado R, Rimmer J, Sewell WA, Harvey RJ. Systemic predictors of eosinophilic chronic rhinosinusitis. Am J Rhinol Allergy. 2018:32:252-7.

32. Tokunaga T, Sakashita M, Haruna T, Asaka D, Takeno S, Ikeda H, et al. Novel scoring system and algorithm for classifying chronic rhinosinusitis: the JESREC Study. Allergy. 2015;70:995-1003.

33. De Corso E, Lucidi D, Battista M, Romanello M, De Vita C, Baroni S, et al. Prognostic value of nasal cytology and clinical factors in nasal polyps development in patients at risk: can the beginning predict the end? Int Forum Allergy Rhinol. 2017;7:861-7

34. Ikeda K, Shiozawa A, Ono N, Kusunoki T, Hirotsu M, Homma H, et al. Subclassification of chronic rhinosinusitis with nasal polyp based on eosinophil and neutrophil. Laryngoscope. 2013;123:E1-9.

35. Persson EK, Verstraete K, Heyndrickx I, Gevaert E, Aegerter H, Percier JM, et al. Protein crystallization promotes type 2 immunity and is reversible by antibody treatment. Science. 2019. https://doi.org/10.1126/scien ce.aaw4295.

36. Virkud YV, Kelly RS, Croteau-Chonka DC, Celedon JC, Dahlin A, Avila L, et al. Novel eosinophilic gene expression networks associated with IgE in two distinct asthma populations. Clin Exp Allergy. 2018;48:1654-64.

37. Wu D, Yan B, Wang Y, Zhang L, Wang C. Charcot-Leyden crystal concentration in nasal secretions predicts clinical response to glucocorticoids in patients with chronic rhinosinusitis with nasal polyps. J Allergy Clin Immunol. 2019;144(345-8):e348. 
38. Li Z, Zeng M, Deng Y, Zhao J, Zhou X, Trudeau JB, et al. 15-Lipoxygenase 1 in nasal polyps promotes CCL26/eotaxin 3 expression through extracellular signal-regulated kinase activation. J Allergy Clin Immunol. 2019;144:1228-411

39. Åsa B, Ylva T, Stina F, et al. On the biosynthesis of 15-HETE and eoxin C4 by human airway epithelial cells. Prostaglandins Other Lipid Mediat. 2015;121:83-90

40. Albano GD, Zhao J, Etling EB, et al. IL-13 desensitizes $\beta 2$-adrenergic receptors in human airway epithelial cells through a 15-lipoxygenase/G protein receptor kinase 2 mechanism. J Allergy Clin Immunol. 2015;135:1144-53.e9.

41. Zhao J, O'Donnell VB, Balzar S, et al. 15-Lipoxygenase 1 interacts with phosphatidylethanolamine-binding protein to regulate MAPK signaling in human airway epithelial cells. Proc Natl Acad Sci U S A. 2011;108:14246-511.

42. Lindley AR, Crapster-Pregont M, Liu Y, et al. 12/15-lipoxygenase is an interleukin-13 and interferon- $\gamma$ counterregulated-mediator of allergic airway inflammation. Mediators Inflamm. 2010;2010:1-10.

43. Liu Cheng Xu, Dawei LL, et al. 15-Lipoxygenase-1 induces expression and release of chemokines in cultured human lung epithelial cells. Am J Physiol Lung Cell Mol Physiol. 2009;297:L196-203.

44. Jeon SG, Moon H-G, Kim Y-S, et al. 15-lipoxygenase metabolites play an important role in the development of a T-helper type 1 allergic inflammation induced by double-stranded RNA. Clin Exp Allergy. 2009;39:908-17.
45. Jinming Z, Ben M, Silvana B, et al. Interleukin-13-induced MUC5AC is regulated by 15 -lipoxygenase 1 pathway in human bronchial epithelial cells. Am J Respir Crit Care Med. 2009;179:782-90.

46. Kristjansson RP, Benonisdottir S, Davidsson OB, Oddsson A, Tragante V, Sigurdsson JK, et al. A loss-of-function variant in ALOX15 protects against nasal polyps and chronic rhinosinusitis. Nat Genet. 2019;51:267-76.

47. Steinke JW, Borish L. Chronic rhinosinusitis phenotypes. Ann Allergy Asthma Immunol. 2016;117:234-40.

48. Braunstahl GJ, Overbeek SE, Kleinjan A, Prins JB, Hoogsteden HC, Fokkens WJ. Nasal allergen provocation induces adhesion molecule expression and tissue eosinophilia in upper and lower airways. J Allergy Clin Immunol. 2001;107:469-76.

49. Ponikau JU, Sherris DA, Kephart GM, Kern EB, Gaffey TA, Tarara JE, et al. Features of airway remodeling and eosinophilic inflammation in chronic rhinosinusitis: is the histopathology similar to asthma? J Allergy Clin Immunol. 2003;112:877-82.

\section{Publisher's Note}

Springer Nature remains neutral with regard to jurisdictional claims in published maps and institutional affiliations.
Ready to submit your research? Choose BMC and benefit from:

- fast, convenient online submission

- thorough peer review by experienced researchers in your field

- rapid publication on acceptance

- support for research data, including large and complex data types

- gold Open Access which fosters wider collaboration and increased citations

- maximum visibility for your research: over 100M website views per year

At BMC, research is always in progress.

Learn more biomedcentral.com/submissions 